\title{
New-particle formation, growth and climate-relevant particle production in Egbert, Canada: analysis from 1 year of size-distribution observations
}

\author{
J. R. Pierce ${ }^{1,2}$, D. M. Westervelt ${ }^{3}$, S. A. Atwood ${ }^{1}$, E. A. Barnes ${ }^{1}$, and W. R. Leaitch ${ }^{4}$ \\ ${ }^{1}$ Department of Atmospheric Science, Colorado State University, Fort Collins, CO, USA \\ ${ }^{2}$ Department of Physics and Atmospheric Science, Dalhousie University, Halifax, NS, Canada \\ ${ }^{3}$ Program in Science, Technology, and Environmental Policy (STEP), Princeton University, Princeton, NJ, USA \\ ${ }^{4}$ Environment Canada, Toronto, Ontario, Canada
}

Correspondence to: J. R. Pierce (jeffrey.pierce@ @olostate.edu)

Received: 2 December 2013 - Published in Atmos. Chem. Phys. Discuss.: 10 January 2014

Revised: 7 July 2014 - Accepted: 16 July 2014 - Published: 26 August 2014

\begin{abstract}
Aerosol particle nucleation, or new-particle formation, is the dominant contributor to particle number in the atmosphere. However, these particles must grow through condensation of low-volatility vapors without coagulating with the larger, preexisting particles in order to reach climaterelevant sizes (diameters larger than 50-100 $\mathrm{nm}$ ), where the particles may affect clouds and radiation. In this paper, we use 1 year of size-distribution measurements from Egbert, Ontario, Canada to calculate the frequency of regional-scale new-particle-formation events, new-particle-formation rates, growth rates and the fraction of new particles that survive to reach climate-relevant sizes. Regional-scale new-particleformation events occur on $14-31 \%$ of the days (depending on the stringency of the classification criteria), with event frequency peaking in the spring and fall. New-particleformation rates and growth rates are similar to those measured at other midlatitude continental sites. We calculate that roughly half of the climate-relevant particles (with diameters larger than 50-100 nm) at Egbert are formed through newparticle-formation events. With the addition of meteorological and $\mathrm{SO}_{2}$ measurements, we find that new-particle formation at Egbert often occurs under synoptic conditions associated with high surface pressure and large-scale subsidence that cause sunny conditions and clean-air flow from the north and west. However, new-particle formation also occurs when air flows from the polluted regions to the south and southwest of Egbert. The new-particle-formation rates tend to be faster during events under the polluted south/southwest flow conditions.
\end{abstract}

\section{Introduction}

Atmospheric aerosols may impact climate directly by scattering and absorbing solar radiation, and indirectly by modifying the albedo and lifetime of clouds (Forster et al., 2007). For both of these effects, aerosol particles with diameters larger than 50-100 $\mathrm{nm}$ dominate the climate effects since (1) in accumulation-mode $(\sim 100-1000 \mathrm{~nm}$ particles) they tend to dominate the direct scattering/absorption effects in most parts of the atmosphere (Charlson et al., 1992; Seinfeld and Pandis, 2006) and (2) because particles larger than about 50 $100 \mathrm{~nm}$ act as cloud condensation nuclei (CCN), the seeds upon which cloud droplets form (e.g., Dusek et al., 2006; Seinfeld and Pandis, 2006). The actual lower cutoff diameter for $\mathrm{CCN}$ depends on the updraft velocity in the cloud and the composition of the aerosols.

Aerosol nucleation, the formation of new $\sim 1 \mathrm{~nm}$ particles by the aggregation of low-volatility vapor molecules (including sulfuric acid, organics, ammonia and water), is likely the largest contributor to aerosol number in the atmosphere (Kulmala et al., 2004; Pierce and Adams, 2009; Spracklen et al., 2006). When nucleated particles grow to sizes where they are measured in the atmosphere (between 1 and $10 \mathrm{~nm}$ depending on the measurement instruments), the phenomena is generally called new-particle formation to distinguish these measured events from nucleation, which is generally not measured directly. New-particle formation has been observed in a large number of continental boundary-layer (BL) locations, 
the free troposphere and some marine locations (e.g., Kulmala et al., 2004, and references therein).

While new-particle formation occurs in many regions of the atmosphere and contributes a significant number of particles, these new particles must grow to larger sizes (50$100 \mathrm{~nm}$ ) in order to have an appreciable effect on climate. The growth of the new particles occurs primarily through the condensation of sulfuric acid vapor and low-volatility organic vapors (Boy et al., 2005; Kuang et al., 2012; Kulmala et al., 2005; Riipinen et al., 2011, 2012). However, these growing particles may be removed, primarily by coagulation with larger particles, before reaching climate-relevant sizes. The competition between condensational growth and coagulative losses has led to the adoption of the term survival probability (SP) for the fraction of newly formed particles that grows to a climate-relevant size without being scavenged through coagulation (Kuang et al., 2009; Pierce and Adams, 2007; Westervelt et al., 2013). In environments with a large source of condensable vapors and a low amount of preexisting particles, new particles grow quickly (both due to the high production of condensable vapors and the low sink of condensable vapors to the preexisting particles) and are lost by coagulation slowly. Under these conditions, the survival probability is high and has been observed to exceed $99 \%$ (to $50 \mathrm{~nm}$ ) in some atmospheric conditions (Westervelt et al., 2013). However, under conditions with a small source of condensable vapors and a high amount of preexisting particles, the survival probability is low and has been observed to be less than $1 \%$ under these conditions (Westervelt et al., 2013). In order to understand how new-particle formation contributes to climate-relevant aerosol concentrations, both new-particleformation rates and survival probabilities must be understood in different atmospheric regions and under varying conditions.

New-particle formation may occur over relatively small spatial scales (kilometers or smaller) in plumes from individual sources or clumps of sources (e.g., an urban plume) (Junkermann et al., 2011; Lonsdale et al., 2012; Stevens and Pierce, 2013; Stevens et al., 2012; Yu, 2010), or it may occur more homogeneously over relatively large spatial scales (hundreds of kilometers) when a synoptic air mass is relatively homogeneous for both aerosols/gases and meteorology (Jeong et al., 2010). For regional-scale new-particle formation, formation and growth rates may be calculated from the time series of aerosol size-distribution measurements at stationary sites (Dal Maso et al., 2005). This is done by observing how the number of particles at the smallest sizes changes with time and by tracking the growth in the diameter of these particles. These properties can be calculated only when the air mass is relatively homogeneous. In air masses that have aerosol size distributions that vary spatially, aerosol size distributions will change due to advection. If the air mass is assumed to be homogeneous in cases where it is not, there may be apparent appearances, disappearances, growth or shrinking of particles that are not due to physical new-particle formation and growth. In these inhomogeneous cases, particles formed via new-particle formation are still observed by stationary measurement sites, but the air-mass properties change too quickly to determine the formation and growth rates.

Recent studies have used observations of regional newparticle formation and growth to determine the survival probability of particles at various measurement sites (Kuang et al., 2009; Westervelt et al., 2013). These studies show that if the air mass over a measurement site is homogeneous for long enough, the growth of new particles to climate-relevant sizes may be explicitly tracked. These direct observations of new-particle-formation rates, growth rates and new-particle survival probability are essential for testing the ability of aerosol microphysics models to correctly predict the sources of $\mathrm{CCN}$ and other climate-relevant particles in the atmosphere. Westervelt et al. (2013) used the observed values from five locations to test multiple nucleation schemes in the GEOS-Chem-TOMAS (Goddard Earth Observing SystemChemical TwO-Moment Aerosol Sectional) global chemical transport model with online aerosol microphysics, and the model generally reproduces new-particle formation and growth frequency and rates at these locations. Additionally, Kerminen et al. (2012) calculated the contribution of newparticle formation to $\mathrm{CCN}$ concentrations at four locations by looking at the change in $\mathrm{CCN}$ concentrations before and after the growing nucleation mode reached a $\mathrm{CCN}$-size threshold. Thus, they were able to calculate the CCN contribution without using growth rates and survival probabilities.

Given that these recent studies have quantified the contribution of regional new-particle-formation events to the production of climate-relevant particles in several locations, it is useful to understand the factors that contribute to the occurrence of regional new-particle-formation events in order to further test model predictions. Previous studies demonstrate that more intense solar radiation (which enhances photochemistry), high concentrations of precursor species of low-volatility condensable material (e.g., $\mathrm{SO}_{2}$ and biogenic volatile organic compounds), and low concentrations of preexisting aerosols (i.e., a low condensation and coagulation sink) all create favorable conditions for regional newparticle formation and growth (Donahue et al., 2011; Kulmala et al., 2005; Pierce et al., 2011, 2012; Sihto et al., 2006). Thus, measurement sites that can provide statistics on newparticle-formation rates, growth rates, survival probabilities along with information on the factors that contribute to newparticle-formation/growth events will provide a basis for testing fundamental physical and chemical processes in aerosol models.

In this study, we use 1 year of size-distribution measurements (May 2007-May 2008) to determine statistics on regional new-particle formation, growth and survival probability to climate-relevant sizes at Egbert, Ontario, Canada. Additionally, we look at the environmental factors that control the occurrence of these events at this location. Egbert 
generally experiences remote continental air when air masses move from the north and generally more polluted when air masses move from the south (Rupakheti et al., 2005); thus, like many midlatitude continental locations, Egbert experiences a mixture of natural and anthropogenic influences (Slowik et al., 2010). New-particle formation at Egbert was explored for a 3-week period with four other Ontario sites (Jeong et al., 2010), and for a full year new-particle formation at Egbert was investigated for coherence with new-particle formation at a site in Indiana, US (Crippa and Pryor, 2013), but neither of these studies presented comprehensive statistics on new-particle formation, growth and the contribution to climate-relevant particles.

In the following section, we describe the methods for our analysis. In Sect. 3, we present our results, including the statistics of new-particle formation, growth and survival probability at Egbert as well as an analysis of the meteorological and chemical factors associated with the new-particle formation and growth events. The conclusions are in Sect. 4.

\section{Methods}

\subsection{Location}

The measurements in this paper were taken from 3 May 2007 until 15 May 2008 at the Center for Atmospheric Research Experiments (CARE) in Egbert, Ontario, Canada (44.23 ${ }^{\circ} \mathrm{N}$, $79.78^{\circ} \mathrm{W} ; 251 \mathrm{~m}$ a.s. 1 - above sea level) operated by Environment Canada. Egbert is located $\sim 70$ miles north of Toronto. While the region close to Egbert is a mixture of forests and farmland, Toronto and the southern Ontario region have $\sim 8$ million people. Thus, when winds are from the south, Egbert is influenced by the outflow from the densely populated southern Ontario region as well as from the US northeast. When winds are from the north, the air generally has little recent anthropogenic influence (an exception is industry in the isolated city of Sudbury $\sim 300 \mathrm{~km}$ to the north) and may have significant biogenic influence during the spring, summer and early fall (Slowik et al., 2010).

\subsection{Instrumentation}

The base meteorological measurements at the Egbert site include pressure, temperature, relative humidity, wind speed and direction (using a R. M. Young Model 05103 Wind Monitor) and solar irradiance. During the 2007-2008 period, the ambient aerosol number size distribution was measured with a scanning mobility particle sizer (SMPS) system comprised of a TSI 3071 Electrostatic Classifier and a TSI 3010 Condensation Particle Counter (UCPC), which measured the size distribution from 10 to $420 \mathrm{~nm}$ with a time resolution of about $5 \mathrm{~min}$. Flows were calibrated with a gilibrator and sizing was checked several times during the year with nearly monodisperse particles generated from a separate electrostatic classifier as well as with particles of polystyrene latex.
Additional details of the SMPS system are discussed in Riipinen et al. (2011). $\mathrm{SO}_{2}$ measurements were made with a TECO 43-S sulfur dioxide monitor. Calibrations were done using a NIST (National Institute of Standards and Technology) traceable $\mathrm{SO}_{2}$ gas source and a dilution system. The detection limit was $200 \mathrm{pptv}$ (parts per trillion by volume) for the 15 min averages that we use here.

\subsection{New-particle formation, growth and survival probability analysis}

\subsubsection{Event classification}

We classify new-particle-formation events of each day using the event classification routine of Dal Maso et al. (2005); a brief description of this classification follows. A total of 327 days are analyzed, which is less than the total number of days (370) because we exclude days that do not have SMPS measurements for at least $75 \%$ of the day's duration (the sample time resolution is $\sim 5 \mathrm{~min}$ ). We classify each day as either a new-particle-formation-event day or a non-event day. To be considered a new-particle-formation-event day a distinct mode of particles with diameters smaller than $20 \mathrm{~nm}$ must appear during the day (regardless of the time at which it appears). This classification (and the event classification described below) is done visually and subjectively as in Dal Maso et al. (2005).

For days that are considered new-particle-formation days, we classify events as class I, class II and undefined event days, also following Dal Maso et al. (2005), with the exception that our class II events encompass both the class II events and the "undefined" events in Dal Maso et al. (2005) as there was a strong continuum between these two event types in the Egbert data (most of the focus of this paper will be on the class Ia and Ib events that may be regional events). However, we do not subclassify class I events to Ia and Ib events as in Dal Maso et al. (2005) as the nucleation mode is generally always distinguishable from the background distribution (Ia events in Dal Maso et al., 2005). Examples of each class are given in Fig. 1; however, even within event classes, there is significant variability between event days in terms of observed behavior.

Class I days (e.g., Fig. 1a) exhibit new-particle formation and an obvious, traceable growth of the nucleation mode to at least $50 \mathrm{~nm}$ before the nucleation mode disappears. Class I days are most likely widespread, regional new-particleformation events with a relatively homogeneous air mass advecting over the Egbert measurement site. The example in Fig. 1 shows an air mass that is not completely homogeneous as the growth in the nucleation mode is not smooth. However, we are still able to retrieve formation and growth rates on these days. 
(a) Sample class I event: 20070924

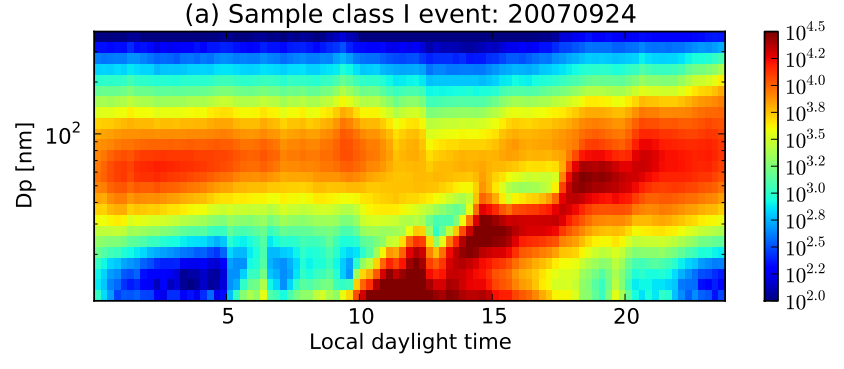

(b) Sample class II event: 20080330

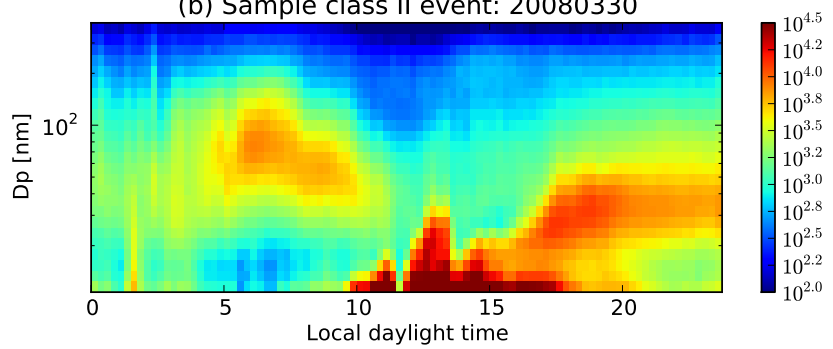

(c) Sample undefined event: 20070512

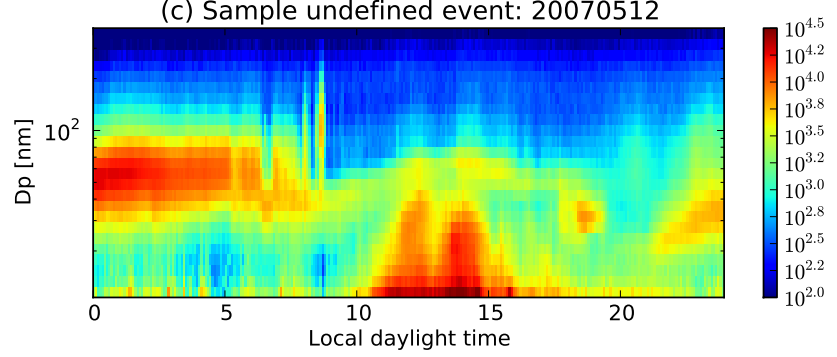

Figure 1. Sample size-distribution time series for a (a) class I nucleation day, (b) class II nucleation day and (c) undefined nucleation day. The color axis $\mathrm{d} N / \mathrm{d} \log D_{p}\left(\mathrm{~cm}^{-3}\right)$.

Class II days (e.g., Fig. 1b) exhibit new-particle formation and some growth (in some cases to over $50 \mathrm{~nm}$ ); however, we do not trust the new-particle formation, growth and survival probability statistics on class II days to the same degree as class I events due to a variety of factors. These factors include possible changes in the air mass during the growth, shrinking after the growth (which may be a sign of a plume event), or it not being clear if the growing particles are the same particles as the newly formed particles (as is the case in Fig. 1b). Class II events may be regional in nature, but the air mass is not homogeneous enough to clearly track new-particle formation and growth from the stationary Egbert site.

Undefined events (e.g., Fig. 2) exhibit particles measured at the smallest sizes of the SMPS, and there is either no growth or there is growth followed by shrinking (as is the case in Fig. 1c). These events may be particles that nucleate across spatial scales smaller than regional-scale events, such as point-source or urban plumes, or they may be regional events in a relatively inhomogeneous or changing air mass. They may also be small primary particles from nearby sources. Cases where particles appear to grow and then shrink may indicate plume nucleation events where the

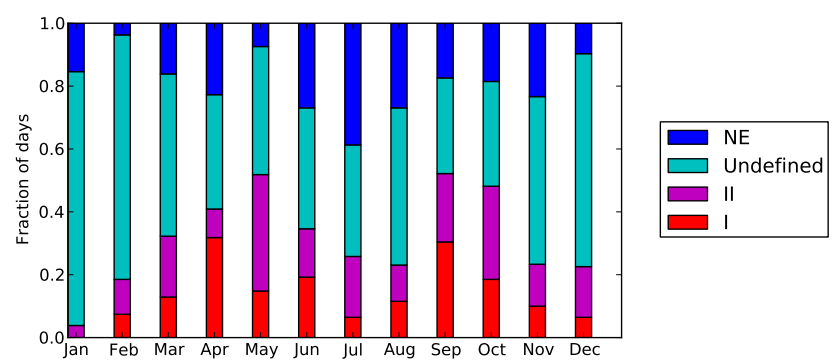

Figure 2. The fraction of days in each month classified as having class I, II and undefined events as well as days with no events (NE). Some days did not have at least $75 \%$ of the day with SMPS data and were not used. All months had at least 22 classified days. Note that multiple undefined events may occur on a given undefined event day. Undefined events may also occur on class I or class II event days; however, these are counted as class I or II days.

direction of the wind changes with time: The smallest particles are observed when the edges of the plume are over the measurement site, and the larger new particles are observed when the center of the plume is over the measurement site. Larger new particles (particles that nucleate closer to the source and have more time to grow) are observed in the middle of plumes with more-recently nucleated particles towards the edges (Stevens et al., 2012).

\subsubsection{New-particle formation and growth rates}

The details of the calculation of new-particle formation and growth rates are discussed in detail in Westervelt et al. (2013) and Kulmala et al. (2012), but we briefly summarize them here. The rate of new $10 \mathrm{~nm}$ particle formation (J10) is calculated from the time-dependent change in the nucleationmode (defined here as $10-25 \mathrm{~nm}$ ) concentrations from the SMPS. We correct these formation rates for the coagulative loss rate of these particles and the loss of particles by condensational growth to sizes larger than $25 \mathrm{~nm}$. The correction for these coagulative and condensational losses increases the calculated J10 from the uncorrected values. We implicitly assume that all particles entering the $10-25 \mathrm{~nm}$ size range are from new-particle formation during class I and II events and not from primary emissions. In this paper, we present $\mathrm{J} 10$ values as both the mean $\mathrm{J} 10$ during the period where newparticle formation is occurring as well as $24 \mathrm{~h}$ mean values to normalize the total particle production between short and long events.

The particle diameter growth rates (GR) are calculated by tracking the change in the diameter of the peak value of the aerosol size distribution for the growing nucleation mode between 10 and $25 \mathrm{~nm}$. We use a linear fit of the peak diameter (defined by maximum concentration) over time to estimate the mean growth rate during the observable growth period. When possible, we also calculate the mean growth rate between 25 and $50 \mathrm{~nm}$ and between 25 and $100 \mathrm{~nm}$ using the 
same technique. Each of these growth rates is used for calculating the survival probability to 50 and $100 \mathrm{~nm}$ (described next). Growth-rate statistics are presented for the $10-25 \mathrm{~nm}$ size range.

\subsubsection{Survival probability and climate-relevant particle formation rates}

We calculate the survival probabilities to 50 and $100 \mathrm{~nm}$ (SP50 and SP100, respectively) by using the Probability of Ultrafine Growth (PUG) model (Pierce and Adams, 2007). These 50 and $100 \mathrm{~nm}$ cutoffs are used as proxies for CCN cutoffs; however, CCN cutoffs also vary as a result of aerosol composition (e.g., Paramonov et al., 2013). The application of the PUG model to SMPS measurements is described in detail in Westervelt et al. (2013). The PUG model calculates the SPs using the mean GRs described above and the coagulation sink of the growing particles to larger, preexisting particles. The coagulation sink represents the first-order loss rate of the growing particles by coagulation, and we calculate it using the measured SMPS size distributions and Brownian coagulation theory (Seinfeld and Pandis, 2006). The PUG model calculates the survival probability over small, incremental steps of growth $(\sim 2 \mathrm{~nm}$ for $10 \mathrm{~nm}$ particles and $\sim 10 \mathrm{~nm}$ for $100 \mathrm{~nm}$ particles; these are the bin spacings of the SMPS) by calculating how many particles will be lost by coagulation in the time it takes the particles to grow by the incremental amount. For each growth step, the coagulation sink is recalculated. The overall survival probabilities to 50 or $100 \mathrm{~nm}$ are calculated as the products of the probabilities of surviving each incremental step.

We calculate the formation rates of climate-relevant particles (J50 and J100) as the product of the J10 with SP50 (for J50) and J10 with SP100 (for J100). We present J50 and J100 as $24 \mathrm{~h}$ mean values rather than the event-mean values to represent the mean climate-relevant particle production rates on event days. These values are used to estimate the total contribution of regional-scale new-particle-formation events to 50 and $100 \mathrm{~nm}$ particle concentrations.

\subsection{Reanalysis meteorology and back trajectories}

We use the NCEP/NCAR Reanalysis (National Centers for Atmospheric Prediction/National Center for Atmospheric Research; Kalnay et al., 1996) to investigate the large-scale meteorology on event days. Specifically, we analyze the fields of $500 \mathrm{hPa}$ geopotential heights, surface pressures and large-scale vertical velocities (omega) at time steps that are the closest to the time of the new-particle-formation events.

In order to assess the meteorological conditions and source regions associated with air masses arriving at Egbert, we utilize back-trajectory analysis. The NOAA HYSPLIT (Hybrid Single Particle Lagrangian Integrated Trajectory model) Lagrangian trajectory model (Draxler, 1999; Draxler and Hess, 1997, 1998) is run using the GDAS (Global Data Assimi- lation System) $1 \times 1^{\circ}$ meteorological data set supplied by the NOAA Air Resources Laboratory. Back trajectories are shown for $24 \mathrm{~h}$ prior to their arrival at $100 \mathrm{~m}$ above ground level at Egbert. We generate eight trajectories per day with the trajectory arriving closest to the period of interest (e.g., the middle of a new-particle-formation event) selected as characteristic of surface level transport at that time. Note that we also examined other arrival heights, but these were found to be similar to the $100 \mathrm{~m}$ heights for trajectories arriving within the boundary layer $(0 \mathrm{~m}, 500 \mathrm{~m})$ and not characteristic of transport to the surface for arrival heights above the typical boundary layer $(1500 \mathrm{~m})$.

\section{Results}

Figure 2 shows the fraction of days in each month that exhibited class I, II, undefined events and non-events. Each month provides at least 22 days with sufficient SMPS data for this analysis (10 months had at least 26$)$. The potentially regional new-particle formation classes, I (observable and quantifiable growth of new particles) and II (similar to I but with less confidence in quantification), exhibit a bimodal seasonal cycle with peaks in the spring and the fall. Either class I or II events occur on about half of the days during the peak seasons and only on about $20 \%$ of the days during summer and winter (except January where there was only one II event and no I events). Most of the class I+II seasonality is driven by the seasonality of the class I events. The winter minimum in class I and II event frequency may be due to a low source of biological volatile organic compounds (BVOCs), precursors for secondary organic aerosols that may be involved in newparticle formation and growth (Riipinen et al., 2011, 2012) as well as lower solar radiation, during cold months. Unfortunately, we do not have measurements of BVOCs or aerosol organics throughout this full time period. The summer minimum may be due to the minimum monthly mean $\mathrm{SO}_{2}$ mixing ratios occurring during July and August. Monthly mean $\mathrm{SO}_{2}$ mixing ratios are $0.6-0.7 \mathrm{ppbv}$ (parts per billion by volume) during these summer months and 1-2 ppbv during the other months. Additionally, a proxy we use for $\mathrm{H}_{2} \mathrm{SO}_{4}$ concentrations (described in Sect. 3.2) also has a minimum during the summer. We go into more detail regarding these factors and the occurrence of new-particle-formation events in Sect. 3.2.

Undefined events (no quantifiable growth after newparticle detection), which may be plume-scale-formation events or plumes of ultrafine primary emissions, tend to be most frequent during the winter. Up to $80 \%$ of the days during the winter and $\sim 35 \%$ of days during the summer are undefined days. As some undefined events occur on days where class I and II events also occur (but these events are ignored here), this may be an upper bound of the seasonal cycle because there may be undefined events hidden in class I and II event days. Note, for days where undefined events occur on class I and II days, we do not include the contribution of 
the undefined events to the class I and II statistics. Regardless, non-event days peak during the summer (nearly $40 \%$ of days during July), which may be related to the low $\mathrm{SO}_{2}$ mixing ratios and $\mathrm{H}_{2} \mathrm{SO}_{4}$ proxy during the summer as mentioned earlier.

\subsection{Particle-formation rates, growth rates and $\mathrm{CCN}$ formation}

Figure 3 shows cumulative distribution functions for J10, GR, SP50, SP100, J50 and J100 for the full year of measurements. The medians and means for these distributions as well as the total number of days in each event class are shown in Table 1. J10 and GR statistics are presented for class I days as well as the sum of class I and II days (we have less confidence in these values due to the inclusion of class II days). We present survival probability, J50 and J100 statistics only for class I days as most class II days do not exhibit growth to at least $50 \mathrm{~nm}$. For J10, we present both the new-particleformation rate averaged over the period where new-particle formation was observed (usually $2-4 \mathrm{~h}$ ) as well as the $24 \mathrm{~h}$ average rate over the day (which leads to values generally 510 times lower than the values during the event period). J50 and $\mathrm{J} 100$ values are the $24 \mathrm{~h}$ average values. The $24 \mathrm{~h}$ average values are useful in that the total daily and annual production rates may be calculated from these values without needing to know the duration of each event.

The event-mean J10 values on class I days range from under $0.1 \mathrm{~cm}^{-3} \mathrm{~s}^{-1}$ to about $10 \mathrm{~cm}^{-3} \mathrm{~s}^{-1}$ with a mean of $0.84 \mathrm{~cm}^{-3} \mathrm{~s}^{-1}$ and median of $0.64 \mathrm{~cm}^{-3} \mathrm{~s}^{-1}$. These values are about $25-50 \%$ lower when class II days are also included due to class II days having somewhat lower particleformation rates in general. As stated above, the $24 \mathrm{~h}$ mean $\mathrm{J} 10$ values are 5-10 times lower than the event-mean values. For class I days, the annual mean and median values of the $24 \mathrm{~h}$ mean formation rates are 0.13 and $0.12 \mathrm{~cm}^{-3} \mathrm{~s}^{-1}$, respectively. The mean, median and data range are consistent with the range of values given for nonurban continental sites in the review paper by Kulmala et al. (2004). Westervelt et al. (2013) presented $24 \mathrm{~h}$ mean new-particle-formation-rate statistics at $3 \mathrm{~nm}(\mathrm{~J} 3)$ for five locations (Pittsburgh, Hyytiälä, Atlanta, St. Louis and the Po Valley) and find that the observed annual means for the $24 \mathrm{~h} \mathrm{~J} 3 \mathrm{~s}$ at these locations range from 0.58 to $8.7 \mathrm{~cm}^{-3} \mathrm{~s}^{-1}$, and the annual medians range from 0.09 to $0.55 \mathrm{~cm}^{-3} \mathrm{~s}^{-1}$. These $\mathrm{J} 3$ values are generally larger than the $\mathrm{J} 10$ values derived here for Egbert; however, $\mathrm{J} 10$ values include the loss of particles by coagulation as the particles grow between 3 and $10 \mathrm{~nm}$, which cause $\mathrm{J} 10$ values to be lower than J3. We estimate the mean survival probability between 3 and $10 \mathrm{~nm}$ to be $25 \%$ for the Egbert study, which gives us estimated mean/median J3s of about $0.5 \mathrm{~cm}^{-3} \mathrm{~s}^{-1}$, in line with the estimates of Westervelt et al. (2013).

Diameter GRs range from less than 0.5 to about $10 \mathrm{~nm} \mathrm{~h}^{-1}$ and are similar on class I and II days. The mean GR is
$3.1 \mathrm{~nm} \mathrm{~h}^{-1}$ and the median is $2.2 \mathrm{~nm} \mathrm{~h}^{-1}$. Again, these mean, median and range of values are consistent with the range of values presented for nonurban continental sites in Kulmala et al. (2004). These mean and median values are at the low end of the range in Westervelt et al. (2013) at the five locations. At these locations, GR means range from 2.8 to $6.9 \mathrm{~nm} \mathrm{~h}^{-1}$ and medians range from 2.4 to $5.8 \mathrm{~nm} \mathrm{~h}^{-1}$. The SP50 values at Egbert range from 1 to close to $100 \%$ depending on the event, and the SP100 values at Egbert range from 0.3 to over $90 \%$ with a mean and median of 19 and $7 \%$ (the mean is higher than the median due to two high outliers, see Fig. 3).

We calculate J50 as the product of J10 and SP50 for each class I event. The J50 values range from 0.001 to about $0.2 \mathrm{~cm}^{-3} \mathrm{~s}^{-1}$, averaged over the full $24 \mathrm{~h}$ of each class I day. The mean and median values are 0.039 and $0.029 \mathrm{~cm}^{-3} \mathrm{~s}^{-1}$, respectively, and lie within the range found at the five sites in Westervelt et al. (2013). Similarly, J100 is calculated as the product of J10 and SP100 for each class I event. The $\mathrm{J} 100$ values range from 0.001 to about $0.2 \mathrm{~cm}^{-3} \mathrm{~s}^{-1}$, averaged over the full $24 \mathrm{~h}$ of each class I event day. The mean and median values are 0.022 and $0.009 \mathrm{~cm}^{-3} \mathrm{~s}^{-1}$, respectively. These values are larger than four of the five sites in Westervelt et al. (2013) (the polluted Po Valley, Italy, site is the exception) due to the larger SP100 values at Egbert. The median formation rates correspond to about $2500 \mathrm{~cm}^{-3}$ new $\mathrm{N} 50$ and $790 \mathrm{~cm}^{-3}$ new N100 on each event day. Compared to the four sites examined in Kerminen et al. (2012), our Egbert climate-relevant particle formation amounts are similar to the amounts at the Botsalano, South Africa, site but are larger than the rates at the three other sites, which are located in northern Europe. However, Kerminen et al. (2012) use a different technique for calculating the contribution of newparticle formation to climate-relevant sizes, which may lead to some differences.

One can use the J50 and J100 values to estimate the contribution of regional new-particle-formation events to the number of climate-relevant particles in the region near Egbert. The formula that we use is as follows:

$\overline{\mathrm{N} 50_{\mathrm{NPF}}}=\frac{\overline{\mathrm{J} 50} \cdot f_{1 \mathrm{a}} \cdot \mathrm{L} 50}{\mathrm{BL}_{\mathrm{rise}}}$.

Where $\mathrm{N} 50_{\mathrm{NPF}}$ is the annual-mean concentration of particles larger than $50 \mathrm{~nm}$ due to regional-scale NPF at Egbert, $\mathrm{J} 50$ is the mean formation rate of $50 \mathrm{~nm}$ particles on class I event days $\left(0.039 \mathrm{~cm}^{-3} \mathrm{~s}^{-1}\right), f_{I}$ is the fraction of analyzed days that are class I event days $(44 / 327=0.135)$, L50 is the lifetime of particles larger than $50 \mathrm{~nm}$ in the boundary layer near Egbert, and $\mathrm{BL}_{\text {rise }}$ is the ratio of the boundary layer height when the nucleation mode reaches $50 \mathrm{~nm}$ to that when it reached $10 \mathrm{~nm}$. Croft et al. (2013) show that the lifetime of $\mathrm{CCN}$-sized particles in the boundary layer in the midlatitudes is around 2-4 days, so we use a value of 3 days. Aircraft measurements of boundary-layer properties near Egbert show that the BLH (boundary layer height) increases from late morning (when the nucleation mode 

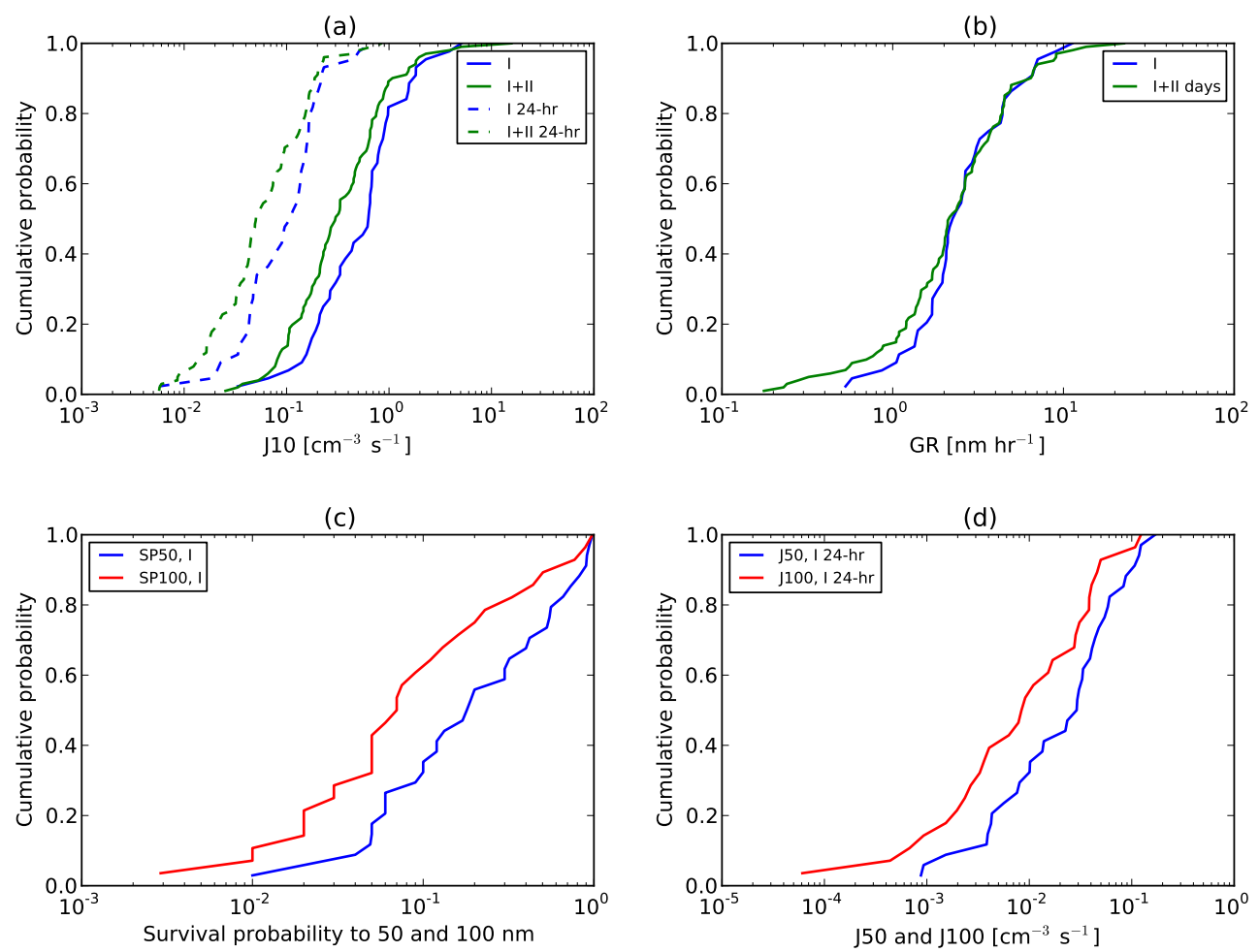

Figure 3. Cumulative probability distributions of various nucleation and growth metrics from the full year. Panel (a): J10 rates for both I days and I + II days. Solid lines show the rates averaged only over the period where nucleation was occurring. Dashed lines show the rates averaged over the full day. Panel (b): growth rates for both I days and I + II days. For the following panels, only I days are shown as we do not trust the estimates of survival probability for II days. Panel (c): survival probability to 50 and $100 \mathrm{~nm}$. Panel (e): $24 \mathrm{~h}$ mean production rate of 50 and $100 \mathrm{~nm}$ particles.

Table 1. Means and medians of nucleation, growth and $\mathrm{CCN}$-formation parameters across all days of each event class.

\begin{tabular}{lllllllll}
\hline Class & No. of days & $\mathrm{J} 10$ & $\mathrm{~J} 10(24 \mathrm{~h})$ & $\mathrm{GR}$ & $\mathrm{SP50}$ & $\mathrm{SP100}$ & $\mathrm{J} 50(24 \mathrm{~h})$ & $\mathrm{J} 100(24 \mathrm{~h})$ \\
\hline & & $\mathrm{cm}^{-3} \mathrm{~s}^{-1}$ & $\mathrm{~cm}^{-3} \mathrm{~s}^{-1}$ & $\mathrm{~nm} \mathrm{~h}$ & $\%$ & $\%$ & $\mathrm{~cm}^{-3} \mathrm{~s}^{-1}$ & $\mathrm{~cm}^{-3} \mathrm{~s}^{-1}$ \\
I (means) & 44 & 0.84 & 0.13 & 3.1 & 33 & 19 & 0.039 & 0.022 \\
I (medians) & 44 & 0.64 & 0.12 & 2.4 & 19 & 7 & 0.029 & 0.0091 \\
II (means) & 57 & 0.58 & 0.069 & 3.1 & N/A & N/A & N/A & N/A \\
II (medians) & 57 & 0.22 & 0.049 & 2.0 & N/A & N/A & N/A & N/A \\
I + II (means) & 101 & 0.69 & 0.097 & 3.1 & N/A & N/A & N/A & N/A \\
I+II (medians) & 101 & 0.30 & 0.050 & 2.2 & N/A & N/A & N/A & N/A \\
\hline
\end{tabular}

generally reaches $10 \mathrm{~nm}$ ) to mid afternoon (when the nucleation mode generally reaches $50 \mathrm{~nm}$ ) by about a factor of 2 , so we set $\mathrm{BL}_{\text {rise }}=2$. With these assumptions, we calculate a $\mathrm{N} 50_{\mathrm{NPF}}$ of $700 \mathrm{~cm}^{-3}$. The mean measured $\mathrm{N} 50$ throughout the entire time period was $1700 \mathrm{~cm}^{-3}$. This means that about $40 \%$ of the N50 in the region around Egbert are formed from regional-scale boundary-layer new-particle-formation events. However, there are uncertainties in $\mathrm{L} 50$ and $\mathrm{BL}_{\text {rise }}$. Thus, the $40 \%$ contribution calculated here could easily be 20 or $60 \%$ within the range of uncertainties of these assumptions. Regardless, it is clear the new-particle formation con- tributes to a significant portion of the climate-relevant particles near Egbert.

We repeat the calculation to estimate $\mathrm{N} 100_{\mathrm{NPF}}$ from $\mathrm{J} 100$. If we assume that $\mathrm{L} 100$ is the same as $\mathrm{L} 50$ and that $\mathrm{BL}_{\text {rise }}$ is the same as the previous calculation, $\mathrm{N} 100_{\mathrm{NPF}}$ is $400 \mathrm{~cm}^{-3}$. The mean measured N100 throughout the entire time period is $710 \mathrm{~cm}^{-3}$. Our estimate of regional-scale boundary-layer new-particle formation to N100 is thus $56 \%$. This estimate is larger than our predicted contribution of regional-scale boundary-layer new-particle formation to N50 (40\%). Primary emissions tend to contribute to a larger fraction of the particles with increasing size, so this result is not physically 
consistent. There are three reasons why our N100 $\mathrm{NPF}$ calculation may be too high relative to our N50 $\mathrm{NPF}$ calculation: (1) the lifetime of $100 \mathrm{~nm}$ particles is likely shorter than $50 \mathrm{~nm}$ particles as $100 \mathrm{~nm}$ particles will act as $\mathrm{CCN}$ in a larger fraction of clouds, and thus $100 \mathrm{~nm}$ particles are more susceptible to wet deposition. (2) The boundary layer may grow in depth between the time the nucleation mode reaches $50 \mathrm{~nm}$ and when it reached $100 \mathrm{~nm}$. (3) The two highest SP100 days shift the mean SP100 (19\%) significantly above the median (7\%). If we had a larger sample of event days, it is possible that the mean would be closer to the median, and the fractional contribution of new-particle formation to $100 \mathrm{~nm}$ particles would be lower than the fractional contribution of new-particle formation to $50 \mathrm{~nm}$ particles.

These estimated contributions of new-particle formation to $\mathrm{CCN}$-sized particles (40-56\%) are similar to the global boundary-layer contribution of new-particle formation to $\mathrm{CCN}$-sized particles estimated in the modeling study by Merikanto et al. (2009); however, they show that much of this contribution is due to new-particle formation in the free troposphere (with subsequent subsidence into the boundary layer) rather than boundary-layer new-particle formation.

\subsection{Conditions during new-particle-formation events}

Figure 4 shows box-and-whisker plots for the atmospheric conditions on each type of event and non-event day. For event days, the values for each variable are taken as the mean value between the start and end of new-particle formation (the period where new particles are arriving at diameters of $\sim 10 \mathrm{~nm}$ ). For non-event days, the values for each variable are taken from the mean time of day for class I new-particleformation events (approximately 11:00-16:00 LST - local standard time) since there is no new-particle-formation event time to draw upon. We display the statistical significance of differences between the distributions of each event class using the Mann-Whitney $U$ test. Although not shown on the plots, the distributions for class I days are statistically different from non-event days to at least the $97 \%$ level for all factors except for temperature $(81 \%)$ and condensation sink $(76 \%)$.

Solar radiation drives photochemistry and thus the oxidation of $\mathrm{SO}_{2}$ to form condensable $\mathrm{H}_{2} \mathrm{SO}_{4}$ and volatile organic compounds to form condensable organic species (Ehn et al., 2014). Previous studies (e.g., Petäjä et al., 2009) have shown that new-particle-formation events are strongly correlated with solar radiation. Solar radiation on class I and II days are significantly higher than undefined and non-event days. All class I events occur between 07:00 and 19:00 LST, and all but 2 (out of 57) II events occur during this time window (not shown). However, 15 (out of 164) undefined events occur outside of this window (not shown) (the nonevent solar radiation stats are taken from $\sim 11: 00-16: 00$ LST the mean event time period for I events). These time-of-day differences explain part of the differences in solar radiation; however, differences in large-scale meteorology (and their effects on cloud cover) between event days are likely important too, as will be shown shortly. Class I days have higher solar radiation than class II days, on average. Thus, similar to the previous studies, the amount of solar radiation likely plays a role in initiating clearly defined regional-scale newparticle-formation events, and nighttime chemistry appears to be less important as class I and II events generally do not occur during dark hours.

While some nucleation theories (e.g., Vehkamäki et al., 2002) predict increasing nucleation rates with relative humidity, the data (as well as other observations, e.g., Hamed et al., 2011, show a general anticorrelation between newparticle formation and relative humidity (relative humidity generally increases moving from class I to II to undefined to non-events). This increase in relative humidity is likely not causally linked to the likelihood of regional-scale newparticle-formation events, but rather (1) clouds are more likely when the relative humidity is higher, (2) the relative humidity is generally higher at night, and (3) the condensation sink generally increases with relative humidity due to aerosol water uptake. While the difference in relative humidity between class I and II events with undefined events and non-events is statistically significant, the difference between the I and II events is not.

Temperature anomalies (difference of the event-time temperature from the 4-week running mean) are mostly positive for class I days (75\% of the events) and the data show a decreasing trend moving from class I to class II to undefined events; however, the difference between successive classes is not significant to the $95 \%$ level. Although the difference between class I events and undefined events is significant, however, some of these differences may be due to differences in the event's time of day. The cause of the higher mean/median temperature anomaly on class I days may be due to clear skies from large-scale meteorology and is consistent with the solar-radiation and relative-humidity statistics (as will be discussed in the next subsection).

Surface-pressure anomalies (also the difference of the event-time pressure from the 4-week running mean) are mostly positive for class I days ( $75 \%$ of the events) with decreasing values moving from class I to II to undefined to non-events. Differences between class I and class II events are not statistically significant, whereas the differences between these event classes with undefined and non-event days are statistically significant. The positive surface-pressure anomaly for $\sim 75 \%$ of the class I events and slightly less than $75 \%$ of the class II events shows that large-scale synoptic meteorology may have played a role in driving many of the regional-scale new-particle-formation events. Surface highs in the midlatitudes are associated with large-scale subsidence in the free troposphere, clear skies and lower-thannormal relative humidities. We will look regionally at differences in large-scale meteorology in the next subsection. 
(a)

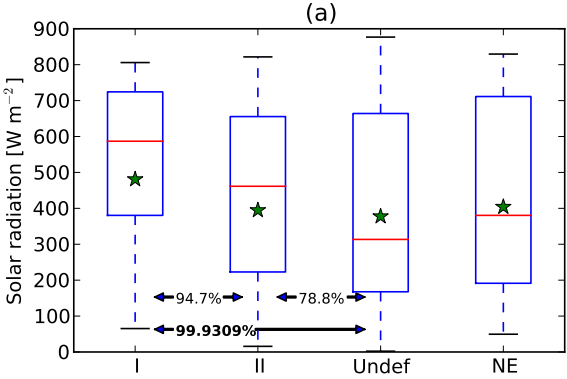

(c)

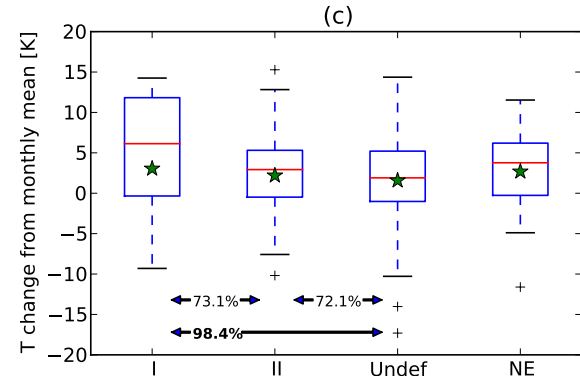

(e)

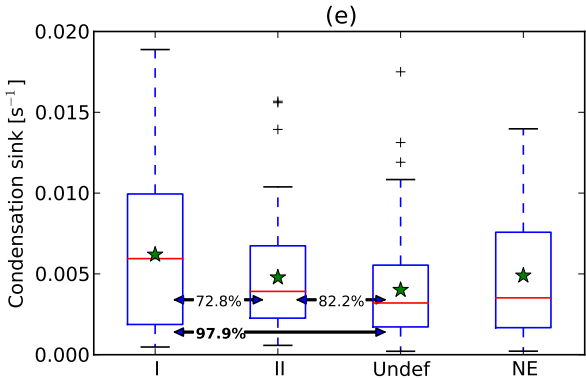

(g)

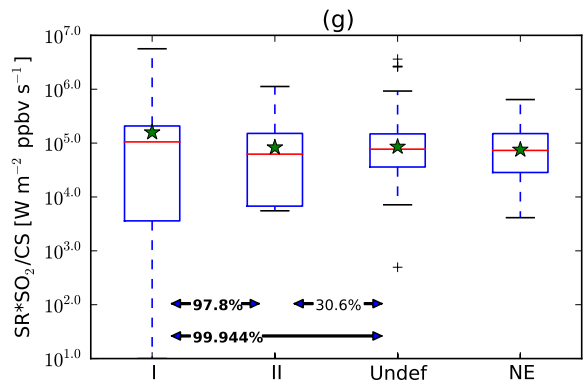

(b)

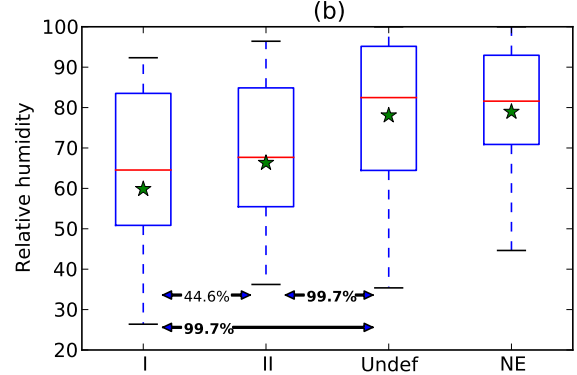

(d)

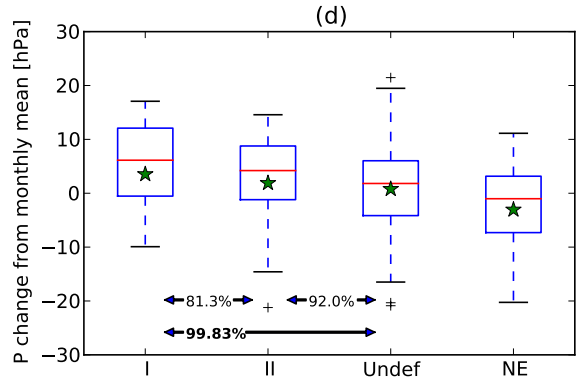

(f)

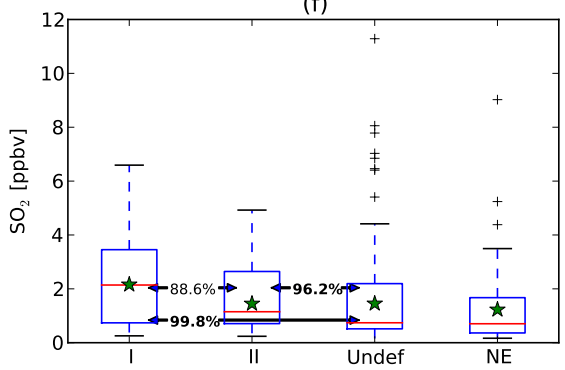

Figure 4. Box-and-whisker plots of various meteorological variables as well as the condensation sink, $\mathrm{SO}_{2}$ mixing ratio and a $\mathrm{H}_{2} \mathrm{SO}_{4}$ proxy for class I, II, undefined and non-event days. The values are calculated between the start and end of new-particle formation on each day except for non-event days where the full day is used. The red line shows the median values. Stars show the mean values. The box shows the interquartile range (IQR, 25th and 75th percentiles). The whiskers show the lowest datum still within the 1.5 IQR of the lower quartile, and the highest datum still within the 1.5 IQR of the upper quartile. Crosses show data outside of the 1.5 IQR above or below the upper or lower quartile. The percentages shown in between each box show the probability that the distributions are statistically different (calculated using the Mann-Whitney $U$ test). Although not shown on the plots, the distributions for Ia days are statistically different from non-event days to at least the $98 \%$ level for all factors except condensation sink (89\%). Panel (a) solar radiation, (b) relative humidity, (c) temperature change from the running 28-day mean (14 days before to 14 days after, to remove the seasonal cycle), (d) surface pressure change from the running 28-day mean, (e) condensation sink, (f) $\mathrm{SO}_{2}$ mixing ratio, (g) $\mathrm{H}_{2} \mathrm{SO}_{4}$ proxy ( $\mathrm{SR} \cdot \mathrm{SO}_{2}$ /condensation sink).

The condensation sink is the rate constant for condensation of a nonvolatile condensable species from the vapor phase to the particle phase. Lower condensation sinks favor newparticle formation and growth because concentrations of condensable species may build up and lead to faster new-particle formation and growth rates. This has been observed in previous studies (e.g., Petäjä et al., 2009; Sihto et al., 2006). However, we find that class I event days have, on average, the highest condensation sinks. The condensation sinks on class I days are higher than on class II days (though only at 
the $73 \%$ significance level) and significantly higher than undefined days (though not significantly higher than non-event days). This means that on the days most likely to have regional new-particle formation and growth at Egbert, the condensation sink is higher compared to other days. A higher condensation sink must be offset by a higher production rate of low-volatility condensable material (e.g., $\mathrm{H}_{2} \mathrm{SO}_{4}$ and lowvolatility organics) to create favorable conditions for newparticle formation and growth. As we discuss in the next subsection, the high-condensation-sink days generally occur when air arrives from the heavily populated region to the south of Egbert.

The concentrations of $\mathrm{SO}_{2}$, the precursor to condensable $\mathrm{H}_{2} \mathrm{SO}_{4}$ vapor, are highest on average on class I event days followed by class II, undefined and non-event days. Class I days are not significantly higher (only $88.6 \%$ significant) than class II days, but they are significantly higher than undefined and non-event days. Undefined event days however, have five high-concentration outliers that exceed all of the class I and II measurements. These class II event results may be indicative of plume-scale new-particle formation in a coalfired power plant or of some other sulfur-rich plume (Junkermann et al., 2011; Lonsdale et al., 2012; Stevens et al., 2012; $\mathrm{Yu}, 2010)$. In the next subsection, we will show that the higher $\mathrm{SO}_{2}$ days generally occur when air arrives from the heavily populated region to the south of Egbert, similar to the condensation sink.

Finally, we use a proxy for $\mathrm{H}_{2} \mathrm{SO}_{4}$ concentration (Petäjä et al., 2009; Rohrer and Berresheim, 2006; Weber et al., 1997) to determine if $\mathrm{H}_{2} \mathrm{SO}_{4}$ concentrations are higher during regional new-particle-formation events than during other days. The proxy we use is

$\left[\mathrm{H}_{2} \mathrm{SO}_{4}\right] \propto \frac{\mathrm{SR} \cdot\left[\mathrm{SO}_{2} \cdot\right]}{\mathrm{CS}}$

Where SR is the solar radiation and CS is the condensation sink. Note, this proxy is plotted on a log scale. Although the condensation sink is highest on average for class I events, the $\mathrm{H}_{2} \mathrm{SO}_{4}$ proxy is highest on average for class I days because both $\mathrm{SR}$ and $\mathrm{SO}_{2}$ are highest on average for these days. The distribution of the $\mathrm{H}_{2} \mathrm{SO}_{4}$ proxy on the class I days is significantly different at the $95 \%$ level from class II days (partly because of the higher mean and median, and partly because of the broader distribution). Class I days are statistically different from undefined and non-event days, with higher means and medians.

Unfortunately, we do not have measurements of organics throughout the time period used here, so we are limited to information on sulfuric acid. However, emissions of biogenic volatile organic compounds (precursors for secondary organics that may contribute to new-particle formation and growth - Riipinen et al., 2011, 2012) are more favorable under warmer and sunnier conditions at Egbert (Leaitch et al., 2011) and elsewhere (Paasonen et al., 2013) and thus lead to organic aerosol formation under these conditions. Because
Table 2. Correlation coefficients between environmental factors with J10s and GRs on class I days.

\begin{tabular}{lrr}
\hline & $\log (\mathrm{J} 10)$ & $\log (\mathrm{GR})$ \\
\hline Solar radiation & 0.42 & 0.06 \\
$\mathrm{RH}$ & -0.26 & 0.10 \\
$\mathrm{~T}$ anomaly & 0.27 & 0.16 \\
$\mathrm{P}$ anomaly & -0.14 & -0.03 \\
$\log (\mathrm{condensation} \mathrm{sink})$ & 0.44 & 0.18 \\
$\log \left(\mathrm{SO}_{2}\right.$ mixing ratio $)$ & 0.33 & 0.23 \\
$\log \left(\mathrm{SR}_{\mathrm{SO}} / \mathrm{CS}\right)$ & 0.20 & 0.12 \\
\hline
\end{tabular}

class I events experience the highest amount of solar radiation and temperature anomalies on average, condensation of low-volatility organic vapors to a growing nucleation mode may be more favorable on these days.

While Fig. 4 shows the distributions of environmental factors during events in the various classes, it does not show how new-particle-formation rates (J10) or GRs vary with the values of these factors. Table 2 shows the correlation coefficients of J10 and GR with the seven environmental factors in Fig. 4 on class I days. Because J10s and GRs span several orders of magnitude, we take the log of these quantities as well as the log of condensation sink, $\mathrm{SO}_{2}$ and the $\mathrm{H}_{2} \mathrm{SO}_{4}$ proxy; each of which spans orders of magnitude (additionally, a $\log$ dependence of $\mathbf{J}$ with $\mathrm{H}_{2} \mathrm{SO}_{4}$ is consistent with the nucleation theorem). All of the environmental factors show stronger correlations (or anticorrelations) with J10 than with the GRs. This could be because other independent factors (e.g., the condensation of low-volatility organics) are more important to GRs than to J10s. As would be expected, J10 is positively correlated with solar radiation, $\mathrm{SO}_{2}$ and the $\mathrm{H}_{2} \mathrm{SO}_{4}$ proxy (albeit weakly). Oddly, J10 is also positively correlated with the condensation sink. However, the condensation sink is also positively correlated with $\mathrm{SO}_{2}$ (correlation coefficient $=0.74$, not shown), which offsets the dampening effect of condensation sink and leads to the weak positive correlation with the $\mathrm{H}_{2} \mathrm{SO}_{4}$ proxy. Because the correlation of the $\mathrm{H}_{2} \mathrm{SO}_{4}$ proxy with $\mathrm{J} 10$ is weak, it is likely that other species (e.g., organics) are also contributing to J10s.

\subsection{Large-scale meteorology and back trajectories}

In this section, we look at the regional meteorological features associated with the different types of events. Figure 5 shows the surface-pressure anomaly (differences from the 4week running mean centered on the event day) for the mean of class I, II and undefined event days (non-event days show only small deviations from the mean, so we have not plotted non-event days here). Regions with a statistically significant $(95 \%$ confidence relative to randomly chosen sets of days) high-surface-pressure anomaly are shaded in pink, and regions where there is a statistically significant $(95 \%$ confidence) low-surface-pressure anomaly are shaded in blue. 
a) Class I days: Surface pressure anomoly [Pa]

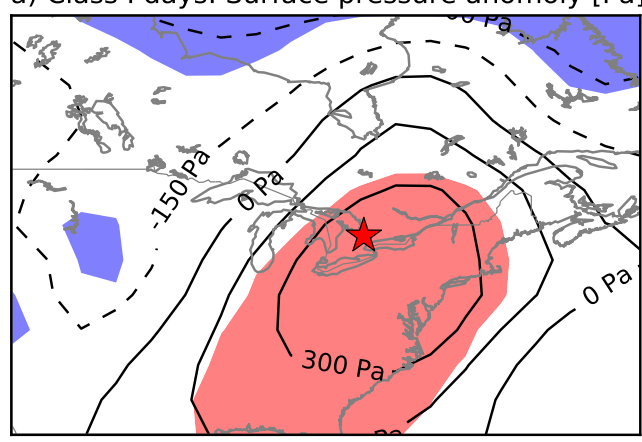

b) Class II days: Surface pressure anomoly [Pa]

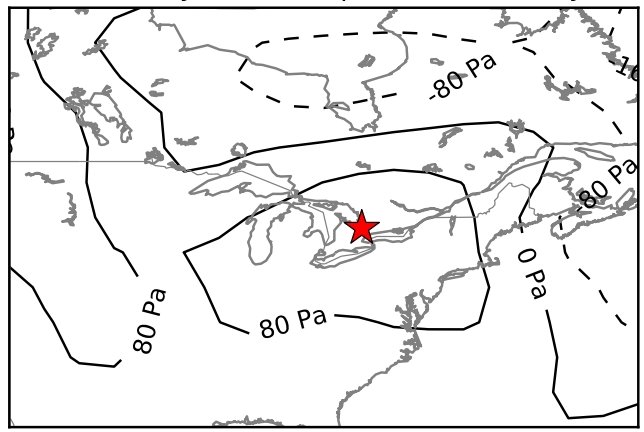

c) Undefined days: Surface pressure anomoly [Pa]

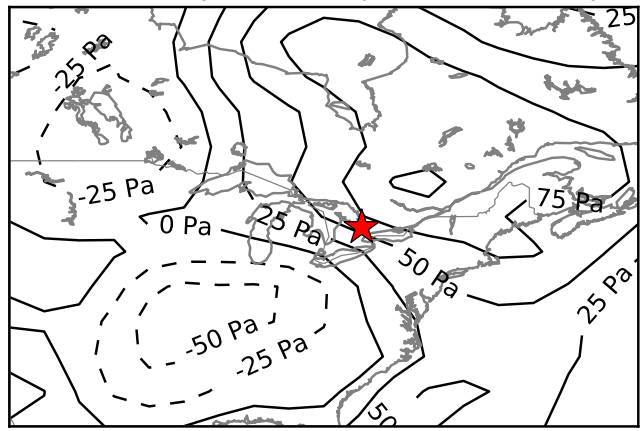

Figure 5. NCEP reanalysis surface-pressure anomaly (Pa) from the 28-day mean for (a) class I, (b) II, and (c) undefined days. Positive $95 \%$ significance anomalies are shaded in pink and negative $95 \%$ significance anomalies are shaded in blue.

Statistical significance is computed following the bootstrap method (Efron, 1979; see Appendix A for details). Consistent with the high-surface-pressure anomalies on class I event days measured at Egbert in Fig. 4c, the entire region around Egbert exhibits a significant surface-pressure anomaly of more than $300 \mathrm{~Pa}$. Although not shown in Fig. 5, Egbert is located inside a region with a $99.8 \%$ significant high anomaly. We note that not all of the 44 class I events exhibit anomalous high pressure over Egbert. Of the class I event days, $25 \%$ experienced low-pressure anomalies at the site (Fig. 4d). Class II events also exhibit a positive surface-pressure anomaly $(150 \mathrm{hPa})$ but this pattern is not statistically different from a) Class I days: $500 \mathrm{mb}$ height $[\mathrm{m}]$

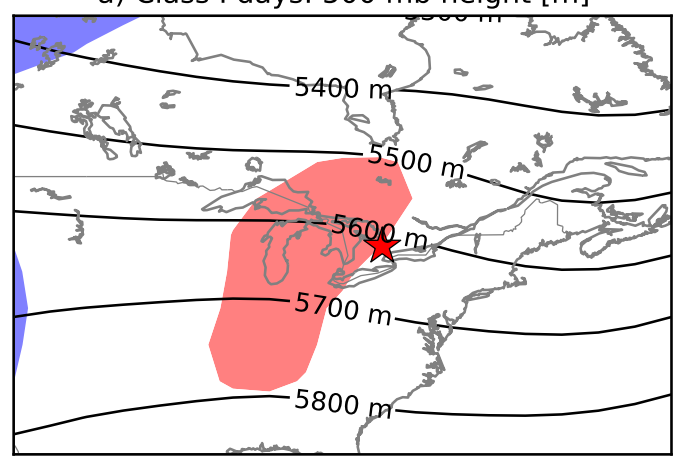

b) Class II days: $500 \mathrm{mb}$ height [m]

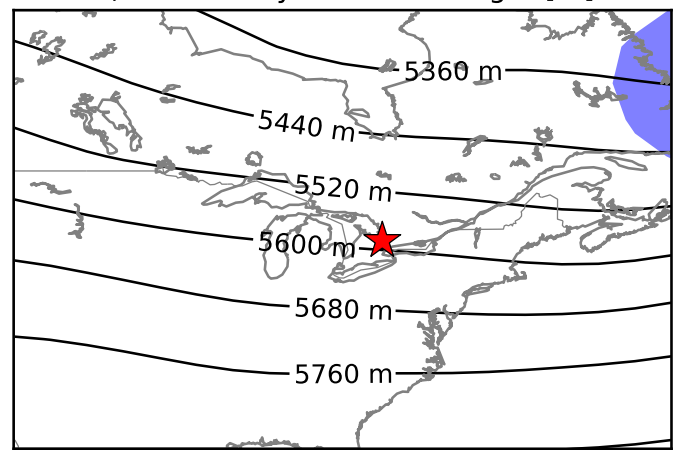

C) Undefined days: $500 \mathrm{mb}$ height $[\mathrm{m}]$

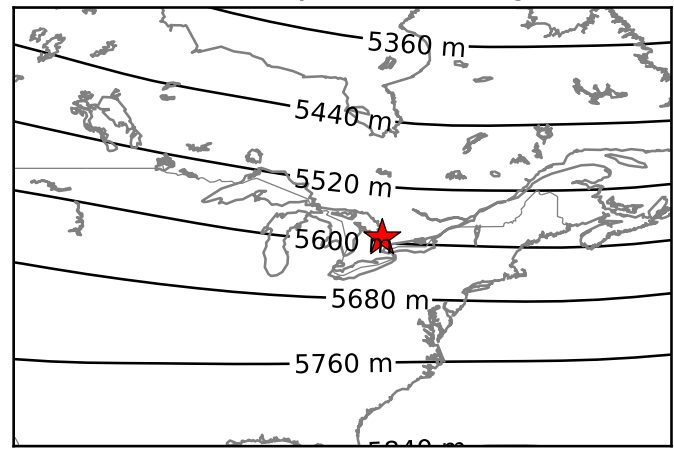

Figure 6. NCEP reanalysis mean $500 \mathrm{mb}$ geopotential heights $(\mathrm{m})$ for (a) class I, (b) II, and (c) undefined days. Positive $95 \%$ significance anomalies are shaded in pink and negative $95 \%$ significance anomalies are shaded in blue.

background variations. For undefined events, the composite meteorological surface-pressure pattern is markedly different from that of class I and II events (Fig. 5c). For undefined events, the region of higher surface pressure is located northeast of Egbert, with a region of low surface pressure to the southwest.

Figure 6 shows composites of the full $500 \mathrm{hPa}$ geopotential height field (i.e., the anomalies have been added back to the mean). Similar to Fig. 5, non-event days show only small deviations from the mean, so we have not plotted non-event days in Fig. 6. The pink and blue areas show the regions of 
CS
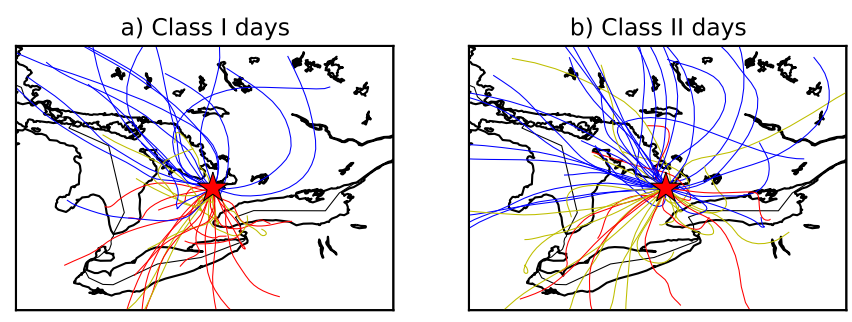

c) Undefined and NE days

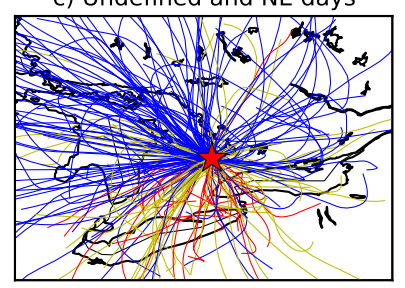

Figure 7. The $24 \mathrm{~h}$ back trajectories arriving during the newparticle-formation event during each class I, II and undefined + nonevent day (one back trajectory per event). Trajectories are colorcoded by the condensation sink measured during the event.

the statistically significant anomalies. There is a statistically significant geopotential height anomaly on class I days west of Egbert, placing Egbert to the east of the ridge. The east sides of the $500 \mathrm{hPa}$ geopotential ridges are associated with tropospheric subsidence and surface highs, consistent with Fig. 5. There are no significant height anomalies in the vicinity of Egbert for the class II or undefined days.

We also investigated the large-scale vertical velocity (omega) fields from NCEP (not shown) and, consistent with the large-scale dynamics shown in Figs. 5 and 6, found statistically significant subsidence over and around Egbert for the class I days. Class II days also showed subsidence over Egbert, but this pattern was not statistically significant. Undefined days showed no major vertical-wind structure.

The NCEP diagnostics shown here suggest that the regional-scale new-particle-formation events (class I) are often associated with the large-scale synoptic pattern with surface highs, large-scale subsidence and a ridge to the west and a trough to the east of Egbert. This is not entirely surprising since these conditions generally bring sunny conditions over the region of subsidence and allow for a homogeneous boundary layer (assuming somewhat spatially homogeneous emissions). These large-scale conditions may explain the measured solar radiation, relative humidity, temperature anomaly and pressure anomaly presented in Fig. 4; however, it is not clear if these conditions also drive the surface-wind directions associated with the highcondensation sink and $\mathrm{SO}_{2}$ concentration seen in class I days in Fig. 4. To explore this, we use HYSPLIT back trajectories.

Figure 7 shows one $24 \mathrm{~h}$ HYSPLIT back trajectory for each new-particle-formation event from the three event classes (non-events are lumped with undefined events here

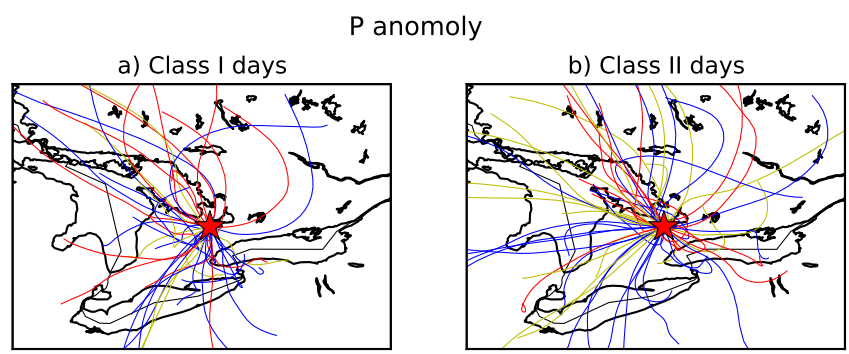

c) Undefined and NE days
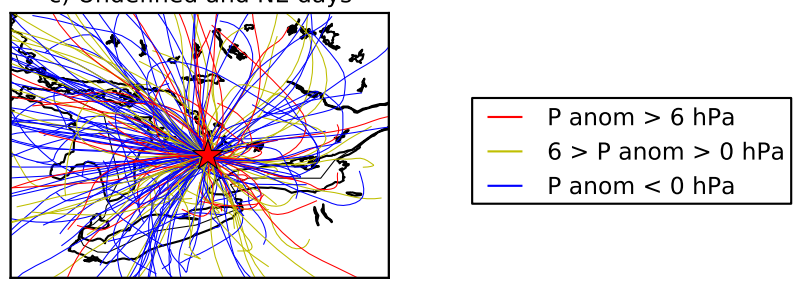

Figure 8. The $24 \mathrm{~h}$ back trajectories arriving during the newparticle-formation event during each class I, II and undefined + nonevent day (one back trajectory per event). Trajectories are colorcoded by the surface-pressure anomaly (from the 28-day running mean) measured during the event.

as their trajectory distributions were similar). The trajectory from each event ends at the hour closest to the middle of the new-particle-formation event (for non-event days, we take 13:00 LST, the mean middle of class I events). The trajectories are colored by the condensation sink during the newparticle-formation event. Air masses for class I events are roughly equally likely to have spent time over regions to the north and south, and they are less likely to have come from the west or east. Class II, undefined events and non-events are roughly equally likely to have spent time over regions to the north, west and south, and somewhat less likely to come from the east. However, for all event classes, higher-condensationsink air generally came from the densely populated regions in the south and lower-condensation-sink air generally from the north. Each event class exhibits cases with both lowerand higher-condensation-sink air. A similar analysis looking at $\mathrm{SO}_{2}$ concentrations rather than the condensation sink (not shown), showed a very similar pattern where high- $\mathrm{SO}_{2}$ air came from the south and low- $\mathrm{SO}_{2}$ air from the north. Thus, air from the south has both high $\mathrm{SO}_{2}$ and a high condensation sink on new-particle-formation days for all event classes, which is consistent with earlier studies at Egbert that found that polluted air most often is from the south (Rupakheti et al., 2005). These results are consistent with the correlation coefficient between $\mathrm{SO}_{2}$ and condensation sink of 0.74 on class I days discussed earlier. Interestingly, the regional-scale new-particle-formation events (class I and maybe class II) are roughly equally likely to occur in clean versus polluted air, which may have been due to the opposing effects of $\mathrm{SO}_{2}$ and the condensation sink on new-particle formation. 
Figure 8 shows the same back trajectories but color-coded by the pressure anomaly. The figure shows that for class I and class II days, the high-pressure-anomaly days are generally associated with air flowing to Egbert from the north. A similar analysis looking at the solar radiation rather than the pressure anomaly (not shown) showed that high solar radiation days are also associated with air flow from the north. Thus, the days with high pressure and solar radiation are generally different from those with high $\mathrm{SO}_{2}$ and condensation sink (although there is some overlap between high pollution and high solar radiation coming from the southeast on class I days).

Taking into account all of the analyses in Sects. 3.2 and 3.3, it appears that regional-scale new-particle formation (class I and possibly class II events) at Egbert occurs under two different sets of conditions: (1) days with the large-scale synoptic meteorology shown in Figs. 5 and 6 with high surface pressure, large-scale subsidence and clear skies generally driving airflow from the clean regions; and (2) days with polluted (yet relatively homogeneously mixed) air flow from the south. For some cases when air comes from the southeast, both of these conditions are satisfied and the air is both polluted and exhibits favorable synoptic conditions. These two conditions for new-particle formation in the region near Egbert was also noted in Jeong et al. 2010), where they looked at new-particle formation at Egbert and three other sites in southern Ontario for 3 weeks during the summer of 2007. As shown in Table 2, we find that $\mathrm{J} 10$ and growth rates are correlated with $\mathrm{SO}_{2}$ and $\mathrm{CS}$, which suggests that the regional new-particle events occurring in the polluted events from the south are generally more intense than the events occurring in the cleaner air from the north.

\section{Summary and conclusions}

In this paper, we use 1 year of aerosol size measurements at Egbert, ON, Canada from May 2007 through to May 2008 to explore new-particle formation and growth to climaterelevant particle sizes at this site. We present both the statistics of formation rates, growth rates and survival probabilities as well as an analysis of the factors that may have contributed to the new-particle formation and growth. We find that the regional-scale new-particle-formation-event frequency peaks in the spring and fall (30-50\% of the days) with minima in the winter and summer. The winter minimum may be due to a lack of biogenic organic precursors to new-particle formation and growth and lower solar radiation while the summer minimum may be due to lower $\mathrm{SO}_{2}$ mixing ratios than the other seasons.

Observed new-particle-formation rates range from less than 0.1 to close to $10 \mathrm{~cm}^{-3} \mathrm{~s}^{-1}$ during the events (and are about 5-10 times lower when averaged over the event day). The $24 \mathrm{~h}$ mean and median values, 0.13 and $0.12 \mathrm{~cm}^{-3} \mathrm{~s}^{-1}$, are within the range of values found at five sites investigated by Westervelt et al. (2013). Growth rates range from less than 0.5 to over $10 \mathrm{~nm} \mathrm{~h}^{-1}$ with mean and median values of 3.1 and $2.0 \mathrm{~nm} \mathrm{~h}^{-1}$, also within the range of Westervelt et al. (2013).

We estimate that the mean formation rates of 50 and $100 \mathrm{~nm}$ particles on regional new-particle-formation days are 0.039 and $0.022 \mathrm{~cm}^{-3} \mathrm{~s}^{-1}$ (averaged over the full day). From this, we estimate that regional new-particle-formation events contribute about half of the climate-relevant particles; however, there is significant uncertainty in our calculation due to uncertainties in aerosol lifetime and changes in the boundarylayer height.

We find that regional new-particle-formation events often occur under synoptic conditions associated with high surface pressure and large-scale subsidence that cause sunny conditions and clean-air flow from the north and west. However, new-particle formation also occurs when air flows from the polluted regions to the south and southwest of Egbert. This air is associated with high $\mathrm{SO}_{2}$ concentrations and high-aerosol-condensation sinks. The new-particleformation rates tend to be faster during events under these south/southwest flow conditions.

A major factor missing from this analysis is the formation rates of secondary organic aerosol (SOA). SOA may form from biogenic volatile organic compounds emitted by vegetation in the region around Egbert or through anthropogenic volatile organic compounds emitted from industry to the south of Egbert. SOA has been shown to be a contributor to both particle formation and growth (Donahue et al., 2011; Metzger et al., 2010; Pierce et al., 2011; Riipinen et al., 2011), and thus variability in SOA formation rates likely contribute to some of the variability in new-particleformation occurrence, new-particle-formation rates, growth rates and survival probabilities reported here. However, we do not have measurements of aerosol composition or of SOA precursor gases for most of the time period explored in this paper and thus do not include it here.

This work provides statistical constraints for testing model predictions of new-particle formation and growth rates (and the driving factors for these rates) at Egbert. Future work will involve comparing the statistics of new-particle formation, growth rates and survival probabilities of an aerosol microphysics model to the measured statistics shown here (similar to what was done in Westervelt et al. 2013). Additionally, these data may be used to test if the meteorological and background chemical factors (e.g., $\mathrm{SO}_{2}$ ) are similar between the simulations and measurements. These comparisons will allow for a comprehensive test of modeled new-particle formation and condensational growth schemes. 
Appendix A: Statistical significance of meteorological patterns

The statistical significance of the meteorological patterns in Figs. 5 and 6 are computed using the bootstrap method (Efron, 1979) to determine if regional-scale new-particleformation events (class I events and possibly class II events) were associated with distinct regional meteorology. We summarize the bootstrap method here. We create 10000 sets of 44 randomly sampled days (the number of class I days; 57 days for class II events and 164 for undefined events) of surface-pressure anomalies, $500 \mathrm{hPa}$ height anomalies and vertical wind anomalies from the NCEP database (from between 1997 and 2009) over the region shown in Figs. 5 and 6. Like in Fig. $4 \mathrm{c}$ and d, the anomalies are defined as differences from the 4-week running mean centered on the event day. We calculate the mean anomalies at each grid point for each of the 10000 sets. Then, at each location, if the observed anomaly falls outside of the 2.5-97.5th percentile range (confidence interval) of the 10000 sample set, we say that the observed anomaly is statistically significant at $95 \%$ confidence using a two-tailed test. 
Acknowledgements. We acknowledge the two anonymous reviewers for their comments that have improved this paper. Funding was provided through Environment Canada's Grants and Contribution program (G\&C 1300358).

Edited by: T. Petäjä

\section{References}

Boy, M., Kulmala, M., Ruuskanen, T. M., Pihlatie, M., Reissell, A., Aalto, P. P., Keronen, P., Dal Maso, M., Hellen, H., Hakola, H., Jansson, R., Hanke, M., and Arnold, F.: Sulphuric acid closure and contribution to nucleation mode particle growth, Atmos. Chem. Phys., 5, 863-878, doi:10.5194/acp-5-863-2005, 2005.

Charlson, R. J., Schwartz, S. E., Hales, J. M., Cess, R. D., Coakley, J. A., Hansen, J. E., and Hofman, D. J.: Climate forcing by anthropogenic aerosols, Science, 255, 423-430, 1992.

Crippa, P. and Pryor, S. C.: Spatial and temporal scales of new particle formation events in eastern North America, Atmos. Environ., available from: http://www.sciencedirect.com/science/article/pii/ S1352231013003051 75, 257-264, 2013.

Croft, B., Pierce, J. R., and Martin, R. V.: Interpreting aerosol lifetimes using the GEOS-Chem model and constraints from radionuclide measurements, Atmos. Chem. Phys. Discuss., 13, 32391-32421, doi:10.5194/acpd-13-32391-2013, 2013.

Dal Maso, M., Kulmala, M., Dal Maso, M., Riipinen, I., Wagner, R., Hussein, T., Aalto, P., and Lehtinen, K. E. J.: Formation and growth of fresh atmospheric aerosols: eight years of aerosol size distribution data from SMEAR II, Hyytiala, Finland, Boreal Env. Res., 10, 323-336, 2005.

Donahue, N. M., Trump, E. R., Pierce, J. R., and Riipinen, I.: Theoretical constraints on pure vapor-pressure driven condensation of organics to ultrafine particles, Geophys. Res. Lett., 38, L16801, doi:10.1029/2011GL048115, 2011.

Draxler, R.: HYSPLIT4 User's Guide, NOAA Tech. Memo. ERL ARL-230, Silver Spring, MD, 1999.

Draxler, R. R. and Hess, G. D.: Description of the HYSPLIT_4 modeling system, NOAA Tech. Memo. ERL ARL-224, NOAA Air Resources Laboratory, Silver Spring, MD, 24 pp., 1997.

Draxler, R. R. and Hess, G. D.: An overview of the HYSPLIT_4 modeling system of trajectories, dispersion, and deposition, Aust. Meteorol. Mag., 47, 295-308, 1998.

Dusek, U., Frank, G. P., Hildebrandt, L., Curtius, J., Schneider, J., Walter, S., Chand, D., Drewnick, F., Hings, S., Jung, D., Borrmann, S., and Andreae, M. O.: Size matters more than chemistry for cloud-nucleating ability of aerosol particles, Science, 312, 1375-1378, 2006.

Efron, B.: Bootstrap methods: another look at the jackknife, Ann. Stat., 7, 1-26, 1979.

Ehn, M., Thornton, J. A, Kleist, E., Sipilä, M., Junninen, H., Pullinen, I., Springer, M., Rubach, F., Tillmann, R., Lee, B., LopezHilfiker, F., Andres, S., Acir, I.-H., Rissanen, M., Jokinen, T., Schobesberger, S., Kangasluoma, J., Kontkanen, J., Nieminen, T., Kurtén, T., Nielsen, L. B., Jørgensen, S., Kjaergaard, H. G., Canagaratna, M., Maso, M. D., Berndt, T., Petäjä, T., Wahner, A., Kerminen, V.-M., Kulmala, M., Worsnop, D. R., Wildt, J. and Mentel, T. F.: A large source of low-volatility secondary organic aerosol., Nature, 506, 476-479, doi:10.1038/nature13032, 2014.
Forster, P., Ramaswamy, V., Artaxo, P., Berntsen, T., Betts, R., Fahey, D. W., Haywood, J., Lean, J., Lowe, D. C., Myhre, G., Nganga, J., Prinn, R., Raga, G., Schulz, M., and Dorland, R. V.: Changes in atmospheric constituents and in radiative forcing, in: Climate Change 2007: The Physical Science Basis. Contribution of Working Group I to the Fourth Assessment Report of the Intergovernmental Panel on Climate Change, edited by: Solomon, S., Qin, D., Manning, M., Chen, Z., Marquis, M., Averyt, K. B., Tignor, M., and Miller, H. L., Cambridge University Press, Cambridge, UK and New York, NY, USA, 129-234, 2007.

Hamed, A., Korhonen, H., Sihto, S.-L., Joutsensaari, J., Järvinen, H., Petäjä, T., Arnold, F., Nieminen, T., Kulmala, M., Smith, J. N., Lehtinen, K. E. J. and Laaksonen, A.: The role of relative humidity in continental new particle formation, J. Geophys. Res., 116, D03202, doi:10.1029/2010JD014186, 2011.

Jeong, C.-H., Evans, G. J., McGuire, M. L., Chang, R. Y.-W., Abbatt, J. P. D., Zeromskiene, K., Mozurkewich, M., Li, S.-M., and Leaitch, W. R.: Particle formation and growth at five rural and urban sites, Atmos. Chem. Phys., 10, 7979-7995, doi:10.5194/acp10-7979-2010, 2010.

Junkermann, W., Vogel, B., and Sutton, M. A.: The climate penalty for clean fossil fuel combustion, Atmos. Chem. Phys., 11, 12917-12924, doi:10.5194/acp-11-12917-2011, 2011.

Kalnay, E., Kanamitsu, M., Kistler, R., Collins, W., Deaven, D., Gandin, L., Iredell, M., Saha, S., White, G., Woollen, J., Zhu, Y., Leetmaa, A., Reynolds, R., Chelliah, M., Ebisuzaki, W., Higgins, W., Janowiak, J., Mo, K. C., Ropelewski, C., Wang, J., Jenne, R., and Joseph, D.: The NCEP/NCAR 40 yr reanalysis project, B. Am. Meteorol. Soc., 77, 437-471, doi:10.1175/15200477(1996)077<0437:TNYRP>2.0.CO;2, 1996.

Kerminen, V.-M., Paramonov, M., Anttila, T., Riipinen, I., Fountoukis, C., Korhonen, H., Asmi, E., Laakso, L., Lihavainen, H., Swietlicki, E., Svenningsson, B., Asmi, A., Pandis, S. N., Kulmala, M., and Petäjä, T.: Cloud condensation nuclei production associated with atmospheric nucleation: a synthesis based on existing literature and new results, Atmos. Chem. Phys., 12, 1203712059, doi:10.5194/acp-12-12037-2012, 2012.

Kuang, C., Chen, M., Zhao, J., Smith, J., McMurry, P. H., and Wang, J.: Size and time-resolved growth rate measurements of 1 to $5 \mathrm{~nm}$ freshly formed atmospheric nuclei, Atmos. Chem. Phys., 12, 3573-3589, doi:10.5194/acp-12-3573-2012, 2012.

Kuang, C., McMurry, P. H., and McCormick, A. V: Determination of cloud condensation nuclei production from measured new particle formation events, Geophys. Res. Lett., 36, L09822, doi:10.1029/2009GL037584, 2009.

Kulmala, M., Petäjä, T., Mönkkönen, P., Koponen, I. K., Dal Maso, M., Aalto, P. P., Lehtinen, K. E. J., and Kerminen, V.M.: On the growth of nucleation mode particles: source rates of condensable vapor in polluted and clean environments, Atmos. Chem. Phys., 5, 409-416, doi:10.5194/acp-5-409-2005, 2005.

Kulmala, M., Vehkamaki, H., Petajda, T., Dal Maso, M., Lauri, A., Kerminen, V. M., Birmili, W., and McMurry, P. H.: Formation and growth rates of ultrafine atmospheric particles: a review of observations, J. Aerosol Sci., 35, 143-176, 2004.

Kulmala, M., Petäjä, T., Nieminen, T., Sipilä, M., Manninen, H. E., Lehtipalo, K., Dal Maso, M., Aalto, P. P., Junninen, H., Paasonen, P., Riipinen, I., Lehtinen, K. E. J., Laaksonen, A., and Kerminen, V.-M.: Measurement of the nucleation 
of atmospheric aerosol particles., Nat. Protoc., 7, 1651-1667, doi:10.1038/nprot.2012.091, 2012.

Leaitch, W. R., Macdonald, A. M., Brickell, P. C., Liggio, J., Sjostedt, S. J., Vlasenko, A., Bottenheim, J. W., Huang, L., Li, S.M., Liu, P. S. K., Toom-Sauntry, D., Hayden, K. A., Sharma, S., Shantz, N. C., Wiebe, H. A., Zhang, W., Abbatt, J. P. D., Slowik, J. G., Chang, R. Y.-W., Russell, L. M., Schwartz, R. E., Takahama, S., Jayne, J. T., and Ng, N. L.: Temperature response of the submicron organic aerosol from temperate forests, Atmos. Environ., available from: http://www.sciencedirect.com/science/ article/pii/S1352231011008843, 45, 6696-6704, 2011.

Lonsdale, C. R., Stevens, R. G., Brock, C. A., Makar, P. A., Knipping, E. M., and Pierce, J. R.: The effect of coal-fired powerplant $\mathrm{SO}_{2}$ and $\mathrm{NO}_{\mathrm{x}}$ control technologies on aerosol nucleation in the source plumes, Atmos. Chem. Phys., 12, 11519-11531, doi:10.5194/acp-12-11519-2012, 2012.

Merikanto, J., Spracklen, D. V., Mann, G. W., Pickering, S. J., and Carslaw, K. S.: Impact of nucleation on global CCN, Atmos. Chem. Phys., 9, 8601-8616, doi:10.5194/acp-9-8601-2009, 2009.

Metzger, A., Verheggen, B., Dommen, J., Duplissy, J., Prevot, A. S. H., Weingartner, E., Riipinen, I., Kulmala, M., Spracklen, D. V, Carslaw, K. S., and Baltensperger, U.: Evidence for the role of organics in aerosol particle formation under atmospheric conditions, P. Natl. Acad. Sci. USA, 107, 6646-6651, doi:10.1073/pnas.0911330107, 2010.

Paasonen, P., Asmi, A., Petäjä, T., Kajos, M. K., Äijälä, M., Junninen, H., Holst, T., Abbatt, J. P. D., Arneth, A., Birmili, W., van der Gon, H. D., Hamed, A., Hoffer, A., Laakso, L., Laaksonen, A., Richard Leaitch, W., Plass-Dülmer, C., Pryor, S. C., Räisänen, P., Swietlicki, E., Wiedensohler, A., Worsnop, D. R., Kerminen, V.-M., and Kulmala, M.: Warming-induced increase in aerosol number concentration likely to moderate climate change, Nat. Geosci., 6, 438-442, doi:10.1038/ngeo1800, 2013.

Paramonov, M., Aalto, P. P., Asmi, A., Prisle, N., Kerminen, V.M., Kulmala, M., and Petäjä, T.: The analysis of size-segregated cloud condensation nuclei counter (CCNC) data and its implications for cloud droplet activation, Atmos. Chem. Phys., 13, 10285-10301, doi:10.5194/acp-13-10285-2013, 2013.

Petäjä, T., Mauldin, III, R. L., Kosciuch, E., McGrath, J., Nieminen, T., Paasonen, P., Boy, M., Adamov, A., Kotiaho, T., and Kulmala, M.: Sulfuric acid and $\mathrm{OH}$ concentrations in a boreal forest site, Atmos. Chem. Phys., 9, 7435-7448, doi:10.5194/acp9-7435-2009, 2009.

Pierce, J. R. and Adams, P. J.: Efficiency of cloud condensation nuclei formation from ultrafine particles, Atmos. Chem. Phys., 7, 1367-1379, doi:10.5194/acp-7-1367-2007, 2007.

Pierce, J. R. and Adams, P. J.: Uncertainty in global CCN concentrations from uncertain aerosol nucleation and primary emission rates, Atmos. Chem. Phys., 9, 1339-1356, doi:10.5194/acp-91339-2009, 2009.

Pierce, J. R., Leaitch, W. R., Liggio, J., Westervelt, D. M., Wainwright, C. D., Abbatt, J. P. D., Ahlm, L., Al-Basheer, W., Cziczo, D. J., Hayden, K. L., Lee, A. K. Y., Li, S.-M., Russell, L. M., Sjostedt, S. J., Strawbridge, K. B., Travis, M., Vlasenko, A., Wentzell, J. J. B., Wiebe, H. A., Wong, J. P. S., and Macdonald, A. M.: Nucleation and condensational growth to $\mathrm{CCN}$ sizes during a sustained pristine biogenic SOA event in a forested mountain valley, Atmos. Chem. Phys., 12, 3147-3163, doi:10.5194/acp-12-3147-2012, 2012.

Pierce, J. R., Riipinen, I., Kulmala, M., Ehn, M., Petäjä, T., Junninen, H., Worsnop, D. R., and Donahue, N. M.: Quantification of the volatility of secondary organic compounds in ultrafine particles during nucleation events, Atmos. Chem. Phys., 11, 90199036, doi:10.5194/acp-11-9019-2011, 2011.

Riipinen, I., Pierce, J. R., Yli-Juuti, T., Nieminen, T., Häkkinen, S., Ehn, M., Junninen, H., Lehtipalo, K., Petäjä, T., Slowik, J., Chang, R., Shantz, N. C., Abbatt, J., Leaitch, W. R., Kerminen, V.-M., Worsnop, D. R., Pandis, S. N., Donahue, N. M., and Kulmala, M.: Organic condensation: a vital link connecting aerosol formation to cloud condensation nuclei (CCN) concentrations, Atmos. Chem. Phys., 11, 3865-3878, doi:10.5194/acp11-3865-2011, 2011.

Riipinen, I., Yli-Juuti, T., Pierce, J. R., Petäjä, T., Worsnop, D. R., Kulmala, M., and Donahue, N. M.: The contribution of organics to atmospheric nanoparticle growth, Nat. Geosci., 5, 453-458, doi:10.1038/ngeo1499, 2012.

Rupakheti, M., Leaitch, W. R., Lohmann, U., Hayden, K., Brickell, P., Lu, G., Li, S.-M., Toom-Sauntry, D., Bottenheim, J. W., Brook, J. R., Vet, R., Jayne, J. T., and Worsnop, D. R.: An intensive study of the size and composition of submicron atmospheric aerosols at a rural site in Ontario, Canada, Aerosol Sci. Tech., 39, 722-736, doi:10.1080/02786820500182420, 2005.

Seinfeld, J. H. and Pandis, S. N.: Atmospheric Chemistry and Physics, 1st edn., John Wiley and Sons, New York, 2006.

Sihto, S.-L., Kulmala, M., Kerminen, V.-M., Dal Maso, M., Petäjä, T., Riipinen, I., Korhonen, H., Arnold, F., Janson, R., Boy, M., Laaksonen, A., and Lehtinen, K. E. J.: Atmospheric sulphuric acid and aerosol formation: implications from atmospheric measurements for nucleation and early growth mechanisms, Atmos. Chem. Phys., 6, 4079-4091, doi:10.5194/acp-64079-2006, 2006.

Slowik, J. G., Stroud, C., Bottenheim, J. W., Brickell, P. C., Chang, R. Y.-W., Liggio, J., Makar, P. A., Martin, R. V., Moran, M. D., Shantz, N. C., Sjostedt, S. J., van Donkelaar, A., Vlasenko, A., Wiebe, H. A., Xia, A. G., Zhang, J., Leaitch, W. R., and Abbatt, J. P. D.: Characterization of a large biogenic secondary organic aerosol event from eastern Canadian forests, Atmos. Chem. Phys., 10, 2825-2845, doi:10.5194/acp-10-28252010, 2010.

Spracklen, D. V., Carslaw, K. S., Kulmala, M., Kerminen, V.-M., Mann, G. W., and Sihto, S.-L.: The contribution of boundary layer nucleation events to total particle concentrations on regional and global scales, Atmos. Chem. Phys., 6, 5631-5648, doi:10.5194/acp-6-5631-2006, 2006.

Stevens, R. G. and Pierce, J. R.: A parameterization of sub-grid particle formation in sulphur-rich plumes for global and regionalscale models, Atmos. Chem. Phys. Discuss., 13, 19583-19623, doi:10.5194/acpd-13-19583-2013, 2013.

Stevens, R. G., Pierce, J. R., Brock, C. A., Reed, M. K., Crawford, J. H., Holloway, J. S., Ryerson, T. B., Huey, L. G., and Nowak, J. B.: Nucleation and growth of sulfate aerosol in coal-fired power plant plumes: sensitivity to background aerosol and meteorology, Atmos. Chem. Phys., 12, 189-206, doi:10.5194/acp-12-189-2012, 2012. 
Vehkamäki, H., Kulmala, M., Napari, I., Lehtinen, K. E. J., Timmreck, C., Noppel, M., and Laaksonen, A.: An improved parameterization for sulfuric acid-water nucleation rates for tropospheric and stratospheric conditions, J. Geophys. Res., 107, 4610-4622, 2002.

Westervelt, D. M., Pierce, J. R., Riipinen, I., Trivitayanurak, W., Hamed, A., Kulmala, M., Laaksonen, A., Decesari, S., and Adams, P. J.: Formation and growth of nucleated particles into cloud condensation nuclei: model-measurement comparison, Atmos. Chem. Phys., 13, 7645-7663, doi:10.5194/acp-13-76452013, 2013.
Yu, F.: Diurnal and seasonal variations of ultrafine particle formation in anthropogenic $\mathrm{SO}_{2}$ plumes, Environ. Sci. Technol., 44, 2011-2015, doi:10.1021/es903228a, 2010. 